\title{
Flavonoids from Citrus unshiu Marc. inhibit cancer cell adhesion to endothelial cells by selective inhibition of VCAM-1
}

\author{
HANA JIN ${ }^{1}$, WON SUP LEE ${ }^{2}$, JEONG WON YUN ${ }^{2}$, JI HYUN JUNG ${ }^{2}$, SANG MI YI $^{2}$, \\ HYE JUNG KIM ${ }^{1}$, YUNG HYUN CHOI ${ }^{5}$, GONSUP KIM ${ }^{6}$, JIN-MYUNG JUNG ${ }^{3}$, \\ CHUNG HO RYU ${ }^{8}$, SUNG CHUL SHIN ${ }^{7}$ and SOON CHAN HONG ${ }^{4}$
}

\author{
Departments of ${ }^{1}$ Pharmacology, ${ }^{2}$ Internal Medicine, ${ }^{3}$ Neurosurgery and ${ }^{4}$ Surgery, Institute of Health Sciences, \\ Gyeongsang National University School of Medicine, Jinju 660-702; ${ }^{5}$ Department of Biochemistry, Dongeui University \\ College of Oriental Medicine and Department of Biomaterial Control (BK21 Program), Dongeui University \\ Graduate School, Busan 614-052; ${ }^{6}$ School of Veterinary Medicine and ${ }^{7}$ Department of Chemistry, and Research \\ Institute of Life Science, Gyeongsang National University; ${ }^{8}$ Division of Applied Life Science (BK21 Program), \\ Institute of Agriculture and Life Science, Gyeongsang National University, Jinju 660-701, Republic of Korea
}

Received July 8, 2013; Accepted August 12, 2013

DOI: $10.3892 /$ or.2013.2711

\begin{abstract}
Citrus fruits have been used as edible fruit and a component of traditional medicine for various diseases including cancer since ancient times. Herein, we investigated the anticancer activity of flavonoids of Citrus unshiu Marc. (FCM) focusing on anti-metastatic effects. We prepared FCM and performed experiments using MDA-MB-231 human breast cancer cells. FCM inhibited TNF-induced cancer cell adhesion to human umbilical vein endothelial cells (HUVECs) without showing any toxicity. FCM inhibited the expression of VCAM-1, but not of ICAM-1, on MDA-MB-231 cells as well as HUVECs. FCM inhibited protein kinase $\mathrm{C}$ (PKC) phosphorylation, but not Akt phosphorylation. FCM also inhibited cancer cell invasion in a dose-dependent manner, but not MMP-9 expression. In conclusion, this study suggested that FCM inhibits TNF-induced cancer cell adhesion to HUVECs by inhibiting VCAM-1 through inhibition of PKC, providing evidence that FCM have anti-metastatic activity by inhibiting adhesion molecules and invasion on human breast cancer cells.
\end{abstract}

Correspondence to: Professor Won Sup Lee, Department of Internal Medicine, Institute of Health Sciences and Gyeongnam Regional Cancer Center, Gyeongsang National University School of Medicine, 90 Chilam-dong, Jinju 660-702, Republic of Korea E-mail: lwshmo@hanmail.net or lwshmo@gshp.gsnu.ac.kr

Professor Hye Jung Kim, Department of Phamacology, Institute of Health Sciences, Gyeongsang National University School of Medicine, 90 Chilam-dong, Jinju 660-702, Republic of Korea E-mail: hyejungkim@gnu.ac.kr

Key words: Citrus unshiu Marc., metastasis, adhesion, VCAM-1, protein kinase $\mathrm{C}$, cancer

\section{Introduction}

With advances in medical science, the population of elderly cancer patients has been increasing. This elderly population has a lack of vital capacity, so they have a higher incidence of serious side effects from conventional chemotherapeutic agents. Therefore, modern chemotherapy strategy is emphasizing quality of life. Recently much interest has been drawn to the possibility of controlling cancer with minimal toxicity using flavonoids from fruit because the flavonoids in fruit can safely enhance anticancer effects (1-3).

Citrus fruits are edible and their dried peels have been used as a component of traditional medicine for various diseases including cancer since ancient times. Citrus unshiu Marc. called 'Kamgyul' in Korean is widely cultivated in Jeju island, Korea. The peels of Citrus unshiu Marc. are used in traditional herbal medicine and frequently prescribed in concert with other herbs for many kinds of disease including cancer. The flavoids isolated from Citrus fruit are mainly composed of hesperidin, naringenin, and nobiletin (4). These compounds have been reported to have some anticancer properties (5). We isolated the flavonoids from the Citrus unshiu Marc. fruit peel (FCM).

Most of cancer patients eventually die of cancer metastasis. Inhibition of the metastatic activity is one of the cancer treatment strategies. Metastasis consists of a series of sequential complicated steps. Initially, cancer cells have to detach from the primary lesion, and invade the basal membrane and move to other lesions though lymphatic system or blood vessels. Before invading the underlying basement membrane, the cancer cells temporarily adhere to endothelial cells, and then extravasate. The ability to adhere to the endothelial cell correlates with the capacity of cancer cells to form metastatic lesions $(6,7)$.

Cell adhesion molecules (CAMs) are involved in a broad range of normal physiological processes, but the pivotal role of CAMs is emphasized by the fact that CAMs are involved in a 
variety of pathologies, especially cancer (8). Most of the cell adhesion molecules (CAMs) belong to four protein families: Ig (immunoglobulin) superfamily (IgSF CAMs), the integrins, the cadherins, and the selectins. Among IgSF CAMs, vascular cell adhesion molecule-1 (VCAM-1) and intracellular adhesion molecule-1 (ICAM-1) are regulated by $\mathrm{NF}-\kappa \mathrm{B}$, closely related in structure, well known endothelial surface adhesion molecules involved in cancer cells (7). However, it has been reported that some highly metastatic cancer cells migrate and adhere to VCAM-1 rather than to ICAM-1 (9), suggesting that VCAM-1 may relate more to cancer metastasis by enhancing the adherence of cancer to endothelial cells. Therefore, it is important to discover that FCM have inhibitory effects on cancer adhesion and the expression of VCAM-1 and ICAM-1. We investigated the anticancer activity of FCM on the ability of cancer to adhere to the endothelial cells and elucidated the mechanism regarding the expression of VCAM-1 and ICAM-1.

\section{Materials and methods}

Preparation of FCM. The flavonoids were isolated from the Citrus unshiu Marc. fruit peel by extraction with $70 \%$ aqueous methanol followed by ethyl acetate elution over a silica gel cartridge. The isolated flavonoids were identified by HPLC using a C18 column. We identified 16 flavonoid components but 2 compounds (hesperetin 7-O-glucoside and hesperetin) were not quantified; a) naringin; b) hesperidin; c) poncirin; d) isosinensetin; e) hexamethoxyflavone; f) sinensetin; g) hexamethoxyflavone; h) tetramethyl-O-isoscutellarein; i) nobiletin; j) 3,30,40,5,6,7,8-heptamethoxyflavone; k) 3-hydroxyhexamethoxyflavone; 1) tangeretin; m) 3-hydroxypentamethoxy-flavone; $\mathrm{n}$ ) hexamethoxyflavone = 54:32:2:0.4: 0.2:1.03:0.2:3.7:1.6:0.4:2.2:0.4:0.2. Among FCM, naringin and hesperidin were the major compounds (1).

Cells and reagents. Human umbilical vein endothelial cells (HUVECs) (EA.hy 926 cells) were obtained from ATCC and grown in medium 199 supplemented with 20\% FBS, $2 \mathrm{mM}$ L-glutamine, $5 \mathrm{U} / \mathrm{ml}$ heparin, $100 \mathrm{IU} / \mathrm{ml}$ penicillin, $10 \mu \mathrm{g} / \mathrm{ml}$ streptomycin and $50 \mu \mathrm{g} / \mathrm{ml}$ EC growth supplements. Cells were cultured in 100-mm dishes and grown in a humidified $5 \% \mathrm{CO}_{2}$ incubator. HUVECs were used between passage number 3 and 6 . The human breast cancer cell line MDA-MB-231, was obtained from the Korea Cell Line Bank (Seoul, Korea) and grown in RPMI1640 supplemented with $10 \%$ FBS, 2 mM L-glutamine, $25 \mathrm{mM}$ N-2-hydroxyethylpiperazine-N'-2-ethanesulfonic acid, $25 \mathrm{mM} \mathrm{NaHCO} 3,100 \mathrm{IU} / \mathrm{ml}$ penicillin and $10 \mu \mathrm{g} / \mathrm{ml}$ streptomycin at $37^{\circ} \mathrm{C}$ in a humidified atmosphere of $95 \%$ air and 5\% $\mathrm{CO}_{2}$. 3-(4,5-Dimethylthiazole-2-yl)-2,5-biphenyl tetrazolium bromide (MTT), 4',6-diamidino-2-phenyindole, dilactate (DAPI), anti- $\beta$-actin antibody were obtained from Sigma-Aldrich Co. (St. Louis, MO, USA). The polyclonal anti-ICAM-1 and VCAM-1 antibodies were purchased from Santa Cruz Biotechnology, Inc. (Santa Cruz, CA, USA). Recombinant human tumor necrosis factor (TNF) was obtained from R\&D Systems (Minneapolis, MN, USA). BD Matrigel $^{\text {TM }}$ basement membrane matrix was supplied by BD Biosciences (San Diego, CA, USA).
Cell viability assay. Cell viability was determined colorimetrically using MTT reagent. Cells were seeded at $10^{4}$ cells/well in 24 -well plates. After treatments, $50 \mu 1$ of $5 \mathrm{mg} / \mathrm{ml}$ MTT solution was added to each well and incubated for $3 \mathrm{~h}$. The supernatants were aspirated and the formazan crystals were dissolved with $200 \mu \mathrm{l}$ of $4 \mathrm{~N} \mathrm{HCl-isopropanol}$ in each well. The optical density of the colored product was measured at $570 \mathrm{~nm}$, as suggested by the manufacturer, using an Infinite 200 microplate reader (Tecan Austria GmbH, Grödig, Austria).

Western blot analysis. The cells were washed in ice-cold PBS and lysed in PRO-PREP protein extraction solution (iNtRON Biotechnology, Seoul, Korea). The samples were centrifugated at $13,000 \mathrm{rpm}$, for $15 \mathrm{~min}$ at $4^{\circ} \mathrm{C}$. An aliquot of the whole cell lysate was subjected to sodium dodecyl sulfate (SDS)-polyacrylamide gel electrophoresis and transferred onto polyvinylidene difluoride membrane. Membranes, blocked with $5 \%$ nonfat milk in Tris-buffered saline (TBS) containing $0.05 \%$ Tween-20 for $2 \mathrm{~h}$ at room temperature, were incubated with anti-ICAM-1 and VCAM-1 antibodies at $1: 1,000$ in TBS containing $0.05 \%$ Tween- 20 and $3 \%$ bovine serum albumin (BSA) for overnight at $4^{\circ} \mathrm{C}$. The membranes were then incubated with horseradish peroxidase-conjugated anti-rabbit $\operatorname{IgG}(1: 5,000)$ antibody for $1 \mathrm{~h}$ at room temperature. After washing, the membranes were developed using the ECL reagent (Bionote, Gyeonggi-do, Korea)

Adhesion assay. HUVECs were seeded into a 6-well plate and treated with the reagents indicated. MDA-MB-231 cells were pelleted and resuspended $\left(7.5 \times 10^{5}\right.$ cells $\left./ \mathrm{ml}\right)$ in RPMI-1640 medium. HUVECs were washed with serum-free medium, and MDA-MB-231 cells were applied onto HUVECs at $37^{\circ} \mathrm{C}$. After $30 \mathrm{~min}$, cell suspensions were withdrawn, and the HUVECs were gently washed with PBS. Adhered MDA-MB-231 cells to HUVECs were counted under a light microscope. Analyses were repeated three times, over the same region, and the results of the three independent experiments were similar.

Matrigel invasion assay. MDA-MB-231 cells were cultured for 3 days. The upper chamber of 24-well cell culture inserts ( $8 \mu \mathrm{m}$ pore size, Falcon, Franklin Lakes, NJ, USA) were washed with a serum-free medium, coated with $100 \mu \mathrm{l}$ of Matrigel $(1 \mathrm{mg} / \mathrm{ml})$ and dried for $30 \mathrm{~min}$ at $37^{\circ} \mathrm{C}$. MDA-MB231 cells treated with FCM were collected; $2 \times 10^{5}$ cells loaded to the upper chambers filled serum-free media, and $500 \mu \mathrm{l}$ of RPMI media containing $10 \%$ FBS was added to the lower chambers. The invasion chambers were incubated for $24 \mathrm{~h}$ in a $37^{\circ} \mathrm{C}$ cell culture incubator. The non-invasive cells that remained on the upper surface of the insert membranes were removed by scrubbing. The cells on the lower insert membranes were stained with DAPI, and cells were counted under the fluorescence microscope. Each sample was measured in triplicate, and each experiment was repeated three times.

Gelatin zymography. Conditioned media collected from MDA-MB-231 cells were concentrated approximately 10-fold with a protein concentrator (Thermo Pierce, Rockford, IL, 

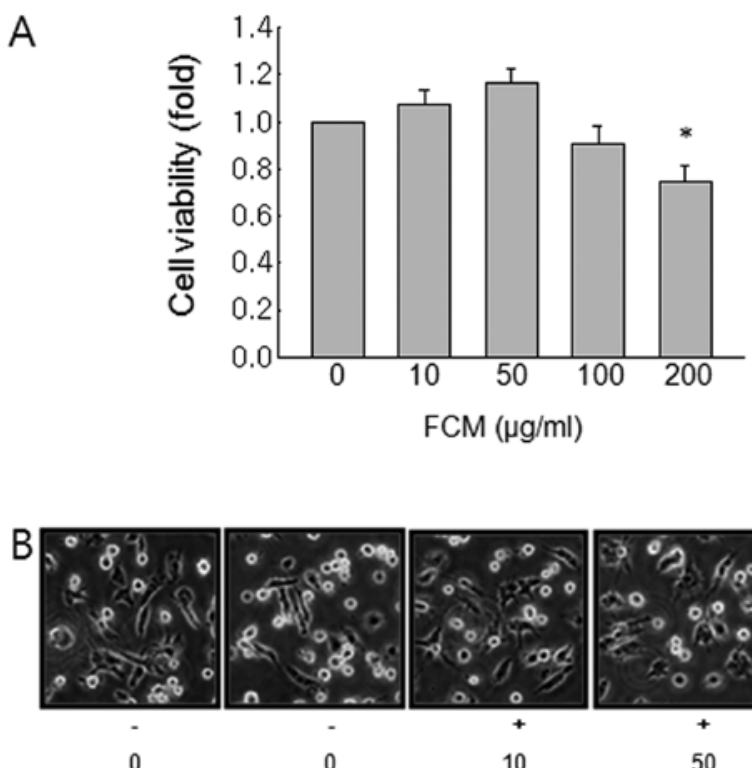

0 0 10


Figure 1. Inhibitory effects of FCM on cancer cell adhesion to HUVECs. MDA-MB-231 cells were seeded at the density of 5x10 4 cells/ml. The cells were treated with indicated concentrations of FCM for $24 \mathrm{~h}$. (A) Cell viability was analysed by MTT assay. (B) HUVECs were starved for $16 \mathrm{~h}$ and then pretreated with FCM at 10,50 or $100 \mu \mathrm{g} / \mathrm{ml}$ for $24 \mathrm{~h}$. Cells were stimulated with TNF (10 ng/ml) for $6 \mathrm{~h}$. HUVECs were washed with serum-free medium, and MDAMB-231 cells were added onto HUVECs and incubated for $30 \mathrm{~min}$ at $37^{\circ} \mathrm{C}$. Cells were gently washed and adhered MDA-MB-231 cells to HUVECs were determined with light microscope (magnification, $\mathrm{x} 200$ ) (A) and quantified (B). Values are the means $\pm \mathrm{SE}$ from three independent determinations. ${ }^{* *}$ p $<0.01$ compared with vehicle-treated group; ${ }^{\# \#} \mathrm{p}<0.01$ compared with TNF-treated group.

USA). Concentrated media were mixed with $2 \mathrm{X}$ sample loading buffer ( $2 \%$ Glycerol, $0.4 \%$ SDS, $0.05 \%$ Bromophenol blue) and subjected to $0.1 \%$ gelatin contained gel electrophoresis without heating. After electrophoresis, gels were incubated with renaturation buffer $(2.5 \%$ Triton $\mathrm{X}-100)$ for $1 \mathrm{~h}$ at room temperature, and then washed with distilled water three times. Gels were applied with developing buffer (50 mM Tris (pH 7.6), $20 \mathrm{mM} \mathrm{NaCl}, 5 \mathrm{mM} \mathrm{CaCl}_{2}, 0.02 \%$ Brij35) overnight at $37^{\circ} \mathrm{C}$, and then washed with distilled water three times. After washing, gels were stained with coomassie blue solution $(0.2 \%$ coomassie brilliant blue, $50 \%$ methanol, $10 \%$ acetic acid) for $1 \mathrm{~h}$ and destained with destaining buffer (50\% methanol, $10 \%$ acetic acid). Gelatinolytic activity was detected as clear bands in the background of blue staining.

Statistical analysis. Each experiment was performed in triplicate. The results were expressed as the means \pm SE. Significant differences were determined using the one-way analysis of variance (ANOVA) with post-test Neuman-Keuls for more than two groups and Student's t-test for two groups. Statistical significance was defined as $\mathrm{p}<0.05$.

\section{Results}

FCM inhibited TNF-induced cancer cell adhesion to human umbilical vein endothelial cells (HUVECs). At first, we assessed anti-proliferative effects of FCM on MDA-MB-231 cells. MTT test revealed that the growth of MDA-MB-231 cells was inhibited by FCM treatment only at a dose of $200 \mu \mathrm{g} / \mathrm{ml}$ (Fig. 1A). Next we performed adhesion assay to test the inhibitory effects on cancer cell adhesion to endothelial cells at the concentrations (10-100 $\mu \mathrm{g} / \mathrm{ml})$ where FCM did not show antiproliferative effects. The adhesion assay revealed that FCM significantly inhibited TNF-induced cancer cell adhesion to HUVECs from the low dose of $10 \mu \mathrm{g} / \mathrm{ml}$ (Fig. 1B).

FCM inhibited VCAM-1 expression, but not ICAM-1 expression. We then assessed the effects of FCM on the expression of VCAM-1 and ICAM-1 to further investigate this finding at the molecular level. Western blot analysis revealed that FCM significantly inhibited VCAM-1 expression, not only in control MDA-MB-231 cells (Fig. 2A and B) but also in TNF-treated MDA-MB-231 cells (Fig. 2C and D). Of note, FCM increased ICAM-1 expression in both the 
A

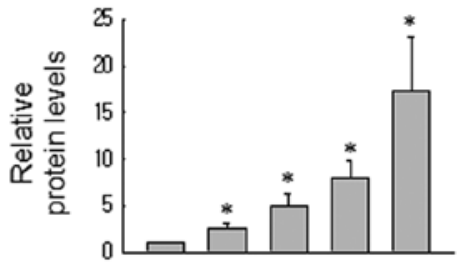

ICAM-1

$\beta$-actin

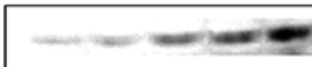

B
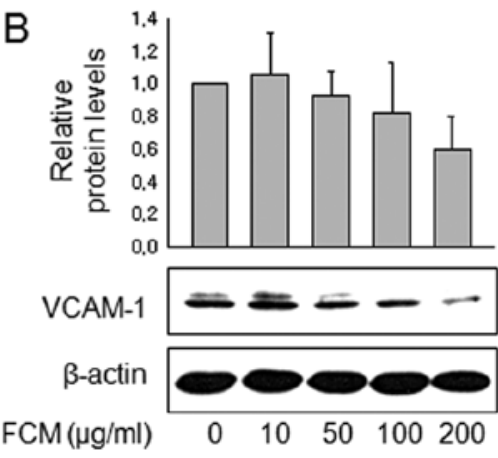

C

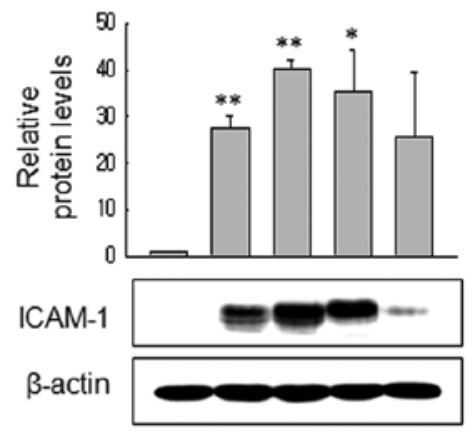

D
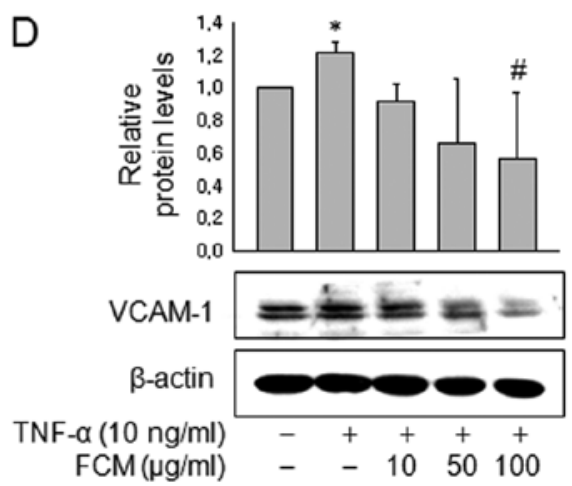

Figure 2. Preferential inhibitory effects of FCM on the expression of VCAM-1 over ICAM-1 in HUVECs. (A and B) MDA-MB-231 were starved for $16 \mathrm{~h}$ and then pretreated with FCM at the indicated concentration. After $24 \mathrm{~h}$ of treatment, proteins were extracted from the cells, and ICAM-1 (A) and VCAM-1 (B) protein levels were determined by western blot analysis and quantified by densitometry. (C and D) MDA-MB-231 cells were starved for $16 \mathrm{~h}$ and then pretreated with FCM at the indicated concentration for $24 \mathrm{~h}$. The cells were then stimulated with TNF (10 ng/ml) for $6 \mathrm{~h}$. After treatments, proteins were extracted from the cells, and ICAM-1 (C), and VCAM-1 (D) protein levels were determined by western blot analysis and quantified by densitometry. Values are the means $\pm \mathrm{SE}$ from three independent determinations. ${ }^{*} \mathrm{p}<0.05,{ }^{* *} \mathrm{p}<0.01$ compared with vehicle-treated group; ${ }^{*} \mathrm{p}<0.05$ compared with TNF-treated group.

A

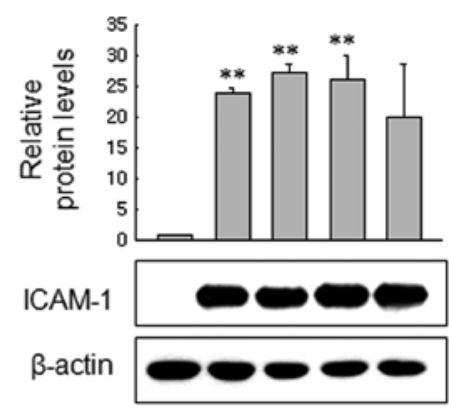

B
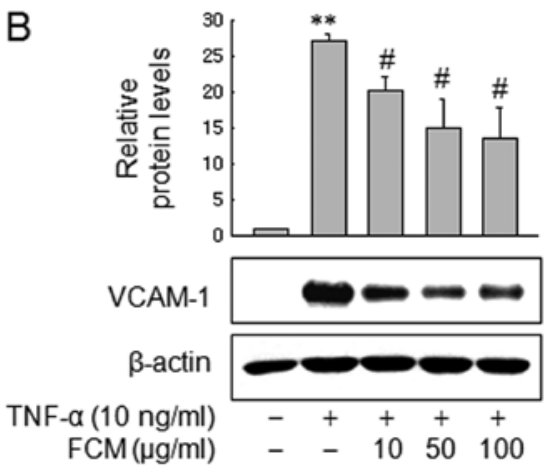

Figure 3. Preferential inhibitory effects of FCM on the expression of VCAM-1 over ICAM-1 in MDA-MB-231 breast cancer cells. HUVECs were starved for $16 \mathrm{~h}$ and then pretreated with FCM at the indicated concentration for $24 \mathrm{~h}$. Cells were then stimulated with TNF $(10 \mathrm{ng} / \mathrm{ml})$ for $6 \mathrm{~h}$. After treatments, proteins were extracted from the cells, and ICAM-1 (A), VCAM-1 (B) protein levels were determined by western blot analysis and quantified by densitometry. Values are the means \pm SE from three independent determinations. " $\mathrm{p}<0.05,{ }^{* *} \mathrm{p}<0.01$ compared with vehicle-treated group; ${ }^{*} \mathrm{p}<0.05$ compared with TNF-treated group.
A

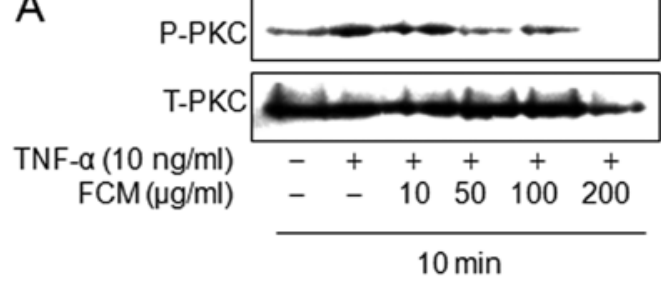

B

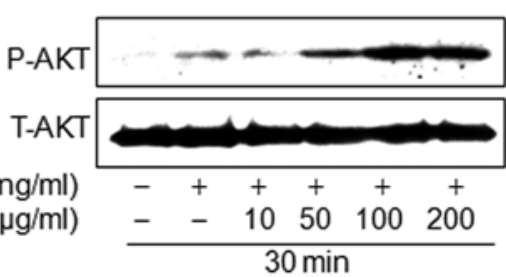

Figure 4. The effects of FCM on phosphorylation of PKC and Akt in MDAMB-231 breast cancer cells. Cells were pretreated with FCM at the indicated concentrations for $24 \mathrm{~h}$, and then treated with TNF for $10 \mathrm{~min}$ for detection of phospho-PKC (A) and for $30 \mathrm{~min}$ for detection of phospho-Akt (B). For reference, total PKC, and Akt blots are used. Cells were extracted and protein level was detected by western blot analysis. Data were confirmed by two independent experiments.

control and TNF-treated MDA-MB-231 cells. Next we also assessed expression of VCAM-1 and ICAM-1 in HUVECs. Consistent with the data in MDA-MB-231 cells, western blot analysis revealed that FCM inhibited VCAM-1 expression 


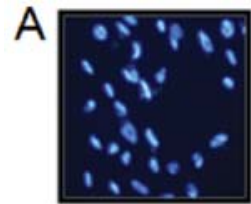

0

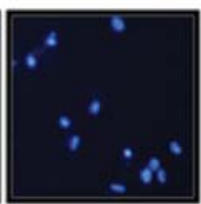

10

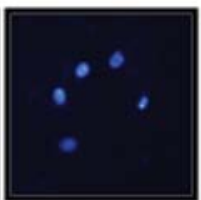

50

$\mathrm{FCM}(\mu \mathrm{g} / \mathrm{ml})$

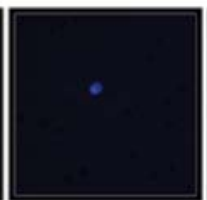

100

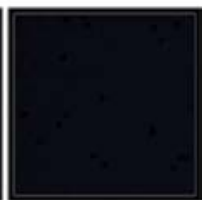

200

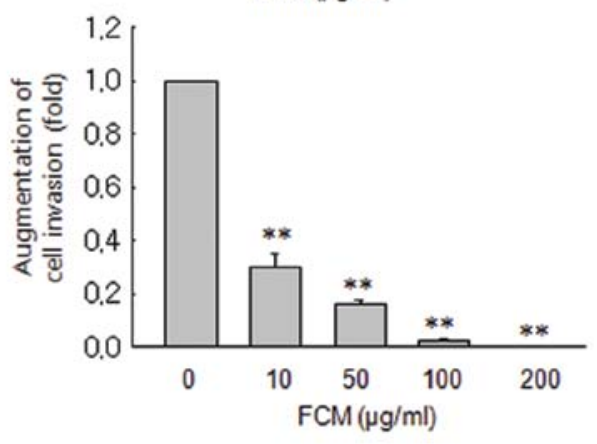

B

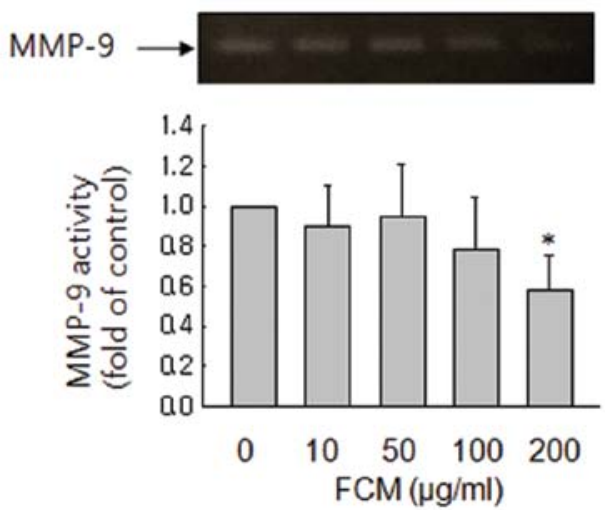

Figure 5. Effects of FCM on cancer cell invasion and MMP-9 expression in MDA-MB-231 cells. MDA-MB-231 cells were starved for $16 \mathrm{~h}$ and then pretreated with FCM as indicated for $24 \mathrm{~h}$. (A) Cells were collected, applied to Matrigel-coated insert well and then incubated for $24 \mathrm{~h}$ at $37^{\circ} \mathrm{C}$. The non-invasive cells were removed and the invasive cells on the lower surface of insert membrane were stained with DAPI. Images from three randomly selected fields are presented. (B) After the treatment, the media were collected and the gelatinolytic activity of MMP-9 was determined with the collected media by gelatin zymography. Values are the means \pm SE from three independent determinations. ${ }^{*} \mathrm{p}<0.05,{ }^{* * *} \mathrm{p}<0.01$ compared with vehicle-treated group.

in a dose-dependent manner, but not ICAM-1 expression (Fig. 3A and B). These findings suggest that FCM may inhibit TNF-induced cancer cell adhesion to HUVECs through inhibiting VCAM-1 expression.

FCM inhibited protein kinase C (PKC) phosphorylation, but not Akt phosphorylation. Of TNF-mediated signaling, PI3K/Akt and PKC signaling pathways are involved in VCAM-1 expression rather than ICAM-1 expression (10). Herein, we investigated the effects of FCM on PI3K/Akt and PKC phosphrylation activated by TNF. Western blotting revealed that FCM inhibited the TNF-induced PKC phosphorylation, but that FCM increased Akt phosphorylation (Fig. 4A and B). These findings suggest that the inhibitory effects of FCM on VCAM-1 expression may be linked to inhibition of TNF-induced PKC phosphorylation, but not Akt phosphorylation.

FCM inhibits cell invasion, but not through inhibition of MMP expression. Activation of PKC induces rapid changes in cell morphology, cell-cell adhesion, and cell migration (11). Therefore, we also performed Matrigel invasion assays to assess the effects of FCM on cancer cell invasion. FCM markedly inhibited cell invasion in a dose-dependent manner (Fig. 5A). To verify the molecular mechanisms, we also measured by gelatin zymographic analyses the activities of the secreted MMP-9 from FCM-treated cancer cells. As shown in Fig. 5B, FCM barely suppressed the gelatinolytic activities of secreted MMP-9, indicating that other mechanisms such as suppression of motility are involved in the inhibitory effects of FCM on cancer invasion.

\section{Discussion}

Adhesive interaction of cancer cells out of blood vessels is an important step in cancer metastasis, because cancer cells are rapidly eliminated from the circulation unless they can adhere to new vasculature to establish new metastatic colonies. Therefore, the adhesion molecules such as ICAM-1 and VCAM-1 are important in the cancer metastasis. This study was designed to investigate the effects of FCM on cancer metastasis. Accordingly we examined the effect of FCM on cancer invasion and adherence in the endothelial cells, 
and elucidated its mechanism regarding the regulation of VCAM-1 and ICAM-1 in MDA-MB 231 human breast cancer cells. MDA-MB 231 cells are a proper model to study cancer metastasis, since the cells are more aggressive, possessing high metastatic potential, and are unresponsive to anti-estrogens due to estrogen receptor negativity (12). In this study, we found that FCM inhibited TNF-induced cancer cell adhesion to human umbilical vein endothelial cells (HUVECs) through inhibiting VCAM-1 expression, and that the inhibitory effects of FCM on VCAM-1 expression appear to be connected to inhibition of protein kinase $\mathrm{C}$ (PKC) phosphorylation induced by TNF.

Previous studies demonstrated TNF induced both ICAM-1 and VCAM-1 proteins on vascular endothelial cells (13). ICAM-1 and VCAM-1 are both regulated by NF- $\kappa$ B. Since $\mathrm{TNF}$ is an NF- $\mathrm{NB}$ stimulator and naringin and hesperidin that are the major components of FCM have some inhibitory

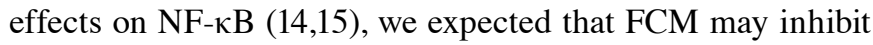
both ICAM-1 and VCAM-1 expression induced by TNF. Of note, however, FCM suppressed the TNF- $\alpha$-induced expression of VCAM-1, but not of ICAM-1. Relating to this result, there is a previous study demonstrating that hesperidin selectively inhibited TNF-induced VCAM-1 expression through suppressing PKC pathway, leading to inhibition of the adhesion of U937 leukemic cells to HUVECs (16). This result is consistent with our results showing the preferential inhibition of VCAM-1 expression over ICAM-1 by FCM. In addition, this study demonstrated that the suppression of VCAM-1 expression was effective in blocking cancer cell adhesion to HUVECs in TNF-stimulated condition. These results were also similar to those of a previous study (17). VCAM-1 and ICAM-1 can be regulated by different signaling pathways, and VCAM-1 is more important in cancer cell adhesion than other adhesion molecules especially for highly metastatic cancer cells (9). Consequently, the suppressive effects of FCM on VCAM-1 expression of endothelial cells as well as cancer cells may be valuable in interfering with cancer metastasis. In this selective suppression of VCAM-1 expression, Akt and PKC are involved (17), and our result showed that FCM inhibit VCAM-1 expression by TNF through regulation of PKC pathway. PKC pathways is well-known to be involved in cancer cell mobility (11). In the process of cancer invasion, cell migration is also required to pass though the basement membrane.

Proteolytic digestion of the extracellular matrix (ECM) by secreted MMPs is one of major steps in cancer invasion $(18,19)$. MMP-9 is also a biomarker for epithelial mesenchymal transition (EMT) (20). When we measured the activities of the secreted MMP-9 from FCM-treated cancer cell by gelatin zymographic analysis, FCM barely suppressed the gelatinolytic activity of secreted MMP-9. This finding suggests that inhibitory effects of FCM on cancer cell invasion may relate to the other mechanisms such as suppression of motility. Besides MMP-9, we also assessed the changes in EMT biomarkers to confirm that FCM have inhibitory effects on EMT (data not shown). Western blotting showed that FCM did not suppress the mesenchymal markers vimentin, and N-cadherin, and that the expression of E-cadherin epithelial marker was not detected in MDA-MB-231 cells (data not shown). In this study, TNF was used to clearly demonstrate the effects of FCM on cancer cell adhesion to HUVECs. Therefore, the pathophysiological relevance that TNF is usually increased in patients with advanced cancers (21) is supporting that TNF-augmented cancer cell adhesion to HUVECs shown in this study is not an artificial in vitro experiment.

In conclusion, this study demonstrated that FCM suppressed the cancer cell adhesion to HUVECs through selective suppression of VCAM-1. The inhibitory effects of FCM on VCAM-1 expression may be linked to inhibition of PKC phosphorylation. This study provides evidence that FCM may have anti-metastatic activity by inhibiting adhesion molecules and invasion on human breast cancer cells.

\section{Acknowledgements}

This study was supported by grants from the National R\&D Program for Cancer Control, Ministry of Health \& Welfare, Republic of Korea (0820050).

\section{References}

1. de Sousa RR, Queiroz KC, Souza AC, Gurgueira SA, Augusto AC Miranda MA, Peppelenbosch MP, Ferreira CV and Aoyama H: Phosphoprotein levels, MAPK activities and NFkappaB expression are affected by fisetin. J Enzyme Inhib Med Chem 22: 439-444, 2007.

2. Liu BL, Zhang X, Zhang W and Zhen HN: New enlightenment of French Paradox: resveratrol's potential for cancer chemoprevention and anti-cancer therapy. Cancer Biol Ther 6: 1833-1836, 2007.

3. Chun KH, Kosmeder JW, Sun S, Pezzuto JM, Lotan R, Hong WK and Lee HY: Effects of deguelin on the phosphatidylinositol 3-kinase/Akt pathway and apoptosis in premalignant human bronchial epithelial cells. J Natl Cancer Inst 95: 291-302, 2003.

4. Nogata Y, Sakamoto K, Shiratsuchi H, Ishii T, Yano M and Ohta H: Flavonoid composition of fruit tissues of citrus species. Biosci Biotechnol Biochem 70: 178-192, 2006.

5. Manthey JA, Grohmann K and Guthrie N: Biological properties of citrus flavonoids pertaining to cancer and inflammation. Curr Med Chem 8: 135-153, 2001.

6. Nicolson GL: Organ specificity of tumor metastasis: role of preferential adhesion, invasion and growth of malignant cells at specific secondary sites. Cancer Metastasis Rev 7: 143-188, 1988.

7. Orr FW, Wang HH, Lafrenie RM, Scherbarth S and Nance DM: Interactions between cancer cells and the endothelium in metastasis. J Pathol 190: 310-329, 2000.

8. Okegawa T, Pong RC, Li Y and Hsieh JT: The role of cell adhesion molecule in cancer progression and its application in cancer therapy. Acta Biochim Pol 51: 445-457, 2004.

9. Klemke M, Weschenfelder T, Konstandin MH and Samstag Y: High affinity interaction of integrin alpha4beta1 (VLA-4) and vascular cell adhesion molecule 1 (VCAM-1) enhances migration of human melanoma cells across activated endothelial cell layers. J Cell Physiol 212: 368-374, 2007.

10. Mun L, Jun MS, Kim YM, Lee YS, Kim HJ, Seo HG, Lee JH, Son KH, Lee DH, Kim YS, Park K and Chang KC: 7,8-Didehydrocimigenol from Cimicifugae rhizoma inhibits TNF-alpha-induced VCAM-1 but not ICAM-1expression through upregulation of PPAR-gamma in human endothelial cells. Food Chem Toxicol 49: 166-172, 2011

11. Weinstein IB, Lee LS, Fisher PB, Mufson A and Yamasaki H: Action of phorbol esters in cell culture: mimicry of transformation, altered differentiation, and effects on cell membranes. J Supramol Struct 12: 195-208, 1979.

12. Anandappa SY, Sibson R, Platt-Higgins A, Winstanley JH, Rudland PS and Barraclough R: Variant estrogen receptor alpha mRNAs in human breast cancer specimens. Int J Cancer 88: 209-216, 2000.

13. Ahmad M, Zhang Y, Papharalambus C and Alexander RW: Role of isoprenylcysteine carboxyl methyltransferase in tumor necrosis factor-alpha stimulation of expression of vascular cell adhesion molecule-1 in endothelial cells. Arterioscler Thromb Vasc Biol 22: 759-764, 2002. 
14. Ang ES, Yang X, Chen H, Liu Q, Zheng MH and Xu J: Naringin abrogates osteoclastogenesis and bone resorption via the inhibition of RANKL-induced NF-kappaB and ERK activation. FEBS Lett 585: 2755-2762, 2011.

15. Ghorbani A, Nazari M, Jeddi-Tehrani M and Zand H: The citrus flavonoid hesperidin induces p53 and inhibits NF-kappaB activation in order to trigger apoptosis in NALM- 6 cells: involvement of PPARgamma-dependent mechanism. Eur J Nutr 51: 39-46, 2012.

16. Nizamutdinova IT, Jeong JJ, Xu GH, Lee SH, Kang SS, Kim YS, Chang KC and Kim HJ: Hesperidin, hesperidin methyl chalone and phellopterin from Poncirus trifoliata (Rutaceae) differentially regulate the expression of adhesion molecules in tumor necrosis factor-alpha-stimulated human umbilical vein endothelial cells. Int Immunopharmacol 8: 670-678, 2008.

17. Sun DI, Nizamutdinova IT, Kim YM, Cai XF, Lee JJ, Kang SS, Kim YS, Kang KM, Chai GY, Chang KC and Kim HJ: Bisacurone inhibits adhesion of inflammatory monocytes or cancer cells to endothelial cells through down-regulation of VCAM-1 expression. Int Immunopharmacol 8: 1272-1281, 2008.
18. Vihinen P and Kahari VM: Matrix metalloproteinases in cancer: prognostic markers and therapeutic targets. Int $\mathbf{J}$ Cancer 99: $157-166,2002$

19. Deryugina EI and Quigley JP: Matrix metalloproteinases and tumor metastasis. Cancer Metastasis Rev 25: 9-34, 2006.

20. Radisky ES and Radisky DC: Matrix metalloproteinase-induced epithelial-mesenchymal transition in breast cancer. J Mammary Gland Biol Neoplasia 15: 201-212, 2010.

21. Correia M, Cravo M, Marques-Vidal P, Grimble R, DiasPereira A, Faias S and Nobre-Leitao C: Serum concentrations of TNF-alpha as a surrogate marker for malnutrition and worse quality of life in patients with gastric cancer. Clin Nutr 26: 728-735, 2007. 